03,09

\title{
Фотонно-кристаллический волновод для генерации второй гармоники
}

\author{
(ㄷ Г.М. Савченко ${ }^{1,2}$, В.В. Дюделев ${ }^{1,3}$, В.В. Лундин ${ }^{1,3}$, А.В. Сахаров ${ }^{1}$, А.Ф. Цацульников ${ }^{4,3}$, \\ Е.А. Когновицкая ${ }^{1}$, С.Н. Лосев ${ }^{1,5}$, А.Г. Дерягин ${ }^{1}$, В.И. Кучинский ${ }^{1,2}$, \\ Н.С. Аверкиев ${ }^{1}$, Г.С. Соколовский ${ }^{1, \uparrow}$ \\ ${ }^{1}$ Физико-технический институт им. А.Ф. Иофрфе РАН, \\ Санкт-Петербург, Россия \\ ${ }^{2}$ Санкт-Петербургский государственный электротехнический университет „ЛЭТИ“, \\ Санкт-Петербург, Россия \\ ${ }^{3}$ Санкт-Петербургский национальный исследовательский университет \\ инфрормационных технологий, механики и оптики, \\ Санкт-Петербург, Россия \\ ${ }^{4}$ Центр микроэлектроники и субмикронных гетероструктур РАН, \\ Санкт-Петербург, Россия \\ ${ }^{5}$ Санкт-Петербургский политехнический университет Петра Великого, \\ Санкт-Петербург, Россия \\ ฯ E-mail: gs@mail.ioffe.ru \\ (Поступила в Редакцию 13 марта 2017 г.)
}

Теоретически показана возможность эффективной генерации второй гармоники в оптическом диапазоне длин волн в плоском диэлектрическом волноводе с активной областью, представляющей собой одномерный фотонный кристалл. Истинный синхронизм фаз достигается за счет управления дисперсией волн в фотонном кристалле. Проведено самосогласованное решение дисперсионных уравнений фотонного кристалла и трехслойного волновода. Показано, что длина когерентности может превышать $10 \mathrm{~mm}$.

Работа выполнена при частичной финансовой поддержке РФФИ (грант № 17-02-00865).

DOI: 10.21883/FTT.2017.09.44836.072

\section{1. Введение}

Как известно, трехслойный диэлектрический волновод обладает набором собственных мод, каждая из которых распространяется под своим углом к плоскости слоев, причем последний зависит от длины волны излучения. Известны так называемые фотонно-кристаллические волноводы, в которых для реализации волноводного эффекта используются фотонные запрещенные зоны. При распространении света по таким волноводам его дисперсия сильно зависит от свойств фотонного кристалла (ФК) и может существенно отличаться от закона дисперсии в обычном трехслойном волноводе. Управление дисперсией света с помощью ФК является одним из приоритетных направлений фотоники [1]. В данной работе представлено теоретическое описание плоского волновода с одномерным ФК в качестве активной области, в котором дисперсия электромагнитных волн обеспечивает истинный синхронизм фаз первой и второй гармоник. Известны публикации, в которых предпринимались попытки увеличить эффективность нелинейного преобразования света во вторую гармонику за счет использования многослойных структур [2,3]. В настоящей работе рассматривается структура, обеспечивающая эффективность преобразования на несколько порядков выше.

Генерация второй гармоники оптического излучения является актуальной задачей нелинейной оптики ввиду отсутствия в настоящее время надежных и компактных источников лазерного излучения для ряда длин волн из оптического диапазона, которые могли бы быть созданы на основе полупроводников. Подобные устройства востребованы в биомедицинской технике, лазерном телевидении и т. д. [4-6].

Главным параметром, отвечающим за эффективность преобразования электромагнитного излучения во вторую гармонику, является длина когерентности

$$
L=\frac{\lambda}{2\left(n_{2 \omega}-n_{\omega}\right)},
$$

где $\lambda$ - длина волны излучения накачки, $n_{\omega}=k_{1} c / \omega$ и $n_{2 \omega}=k_{2} c / \omega-$ эффективные показатели преломления волноводных мод основной частоты и второй гармоники соответственно, $k_{1}$ и $k_{2}$ - модули волновых векторов на основной частоте и второй гармонике. Как известно, дисперсия материалов волновода, а также волноводная дисперсия приводят к невозможности синхронизовать две волны с различными частотами. При распространении по однородному материалу такие волны имеют различные фазовые скорости. В волноводе они соответствуют различным собственным волноводным модам и распространяются под разными углами. Физический смысл длины когерентности состоит в том, что она представляет собой расстояние, на котором излучение накачки и излучение с удвоенной частотой набирают разность 
фаз $\pi$. Далее происходит деструктивная интерференция, снижающая интенсивность преобразованного излучения на выходе из устройства. Поэтому длина когерентности представляет собой критерий синхронизма фаз первой и второй гармоник и является, таким образом, важнейшим параметром, определяющим эффективность преобразования света во вторую гармонику [7].

\section{2. Генерация второй гармоники в бесконечном одномерном фотонном кристалле}

Рассмотрим сначала одномерный ФК, представляющий собой систему из бесконечного числа чередующихся в направлении $O Z$ слоев с толщинами $a$ и $b$, имеющих показатели преломления $n_{1}$ и $n_{2}$ соответственно. В направлениях $O X$ и $O Y$ слои будем считать бесконечными. Показатель преломления такой структуры периодически зависит от координаты в направлении $Z$

$$
n(z)= \begin{cases}n_{1}, & 0 \leq z<a, \\ n_{2}, & -b \leq z<0 .\end{cases}
$$

Амплитуда поля удовлетворяет уравнению Гельмгольца

$$
\Delta E+\frac{\omega^{2}}{c^{2}} \varepsilon(\omega, z) E=0
$$

которое допускает разделение переменных $E(r)=$ $=E(\rho) E(z)$. Здесь $\rho-$ радиус-вектор в плоскости слоев (плоскость $O X Y$ ).

При распространении света по такому ФК электромагнитное поле в кристалле можно представить в блоховском виде

$$
E(z)=U_{k}(z) \exp \left(i k_{z} z\right)+U_{-k}(z) \exp \left(-i k_{z} z\right) .
$$

Условия непрерывности амплитуды поля и ее производной в точках $z=0$ и $z=a$, а также условие периодичности приводят к дисперсионному уравнению

$$
P(\omega, q)=R\left(\omega, k_{z}\right)
$$

где $q-$ волновой вектор в плоскости слоев,

$$
\begin{gathered}
P(\omega, q)=\frac{\left(\varepsilon_{1}(\omega)+\varepsilon_{2}(\omega)\right) k_{0}^{2}-2 q^{2}}{2 \kappa_{1}(\omega) \kappa_{2}(\omega)}\left(\sinh \left(a \kappa_{1}(\omega)\right)\right. \\
\left.\times \sinh \left(b \kappa_{2}(\omega)\right)+\cosh \left(a \kappa_{1}(\omega)\right) \cosh \left(b \kappa_{2}(\omega)\right)\right), \\
k_{0}=\omega / c, \quad \kappa_{i}(\omega)=\sqrt{q^{2}-\varepsilon_{i}(\omega) k_{0}^{2}}, \\
R\left(\omega, k_{z}\right)=\cos k_{z}(a+b) .
\end{gathered}
$$

Анализ уравнения показывает, что закон дисперсии электромагнитной волны в подобном ФК существенным образом зависит от угла ее распространения $\varphi=\arctan \left(k_{z} / q\right)$. В связи с этим подобный ФК можно считать материалом с анизотропным показателем преломления $n=n(\omega, \varphi)$.

Мы считаем, что слои толщиной $a$ представляют собой слои полупроводникового материала, а слои толщиной $b$ - металлические или выполненные из сильнолегированного полупроводника, диэлектрическая проницаемость которого определяется как проницаемость плазмы с характерной плазменной частотой $\omega_{p}$

$$
\varepsilon_{2}(\omega)=1-\omega_{p}^{2} / \omega^{2}
$$

При этом необходимо выполнение условия $\varepsilon_{2}(\omega)<0$. Для полупроводникового материала формально учитывается хроматическая дисперсия с помощью коэффициентов Селлмайера [8].

Главным критерием эффективности генерации второй гармоники в этой системе является длина когерентности, которая может быть вычислена с помощью найденных из формулы (3) значений компонент волнового вектора

$$
L=\frac{\pi}{\left|k_{2}-2 k_{1}\right|},
$$

где $k_{1}=\sqrt{q_{i}^{2}+k_{z i}^{2}}$. В недавней работе [9] было показано, что при надлежащем выборе угла распространения света в ФК длина когерентности может достигать нескольких сантиметров.

\section{3. Расчет собственных мод трехслойного планарного волновода с метаматериалом в активной области}

Теперь рассчитаем собственные моды для трехслойного планарного волновода, в сердцевине которого расположен ФК, описанный в предыдущем разделе. Структура устройства показана на рис. 1.

При распространении света в трехслойном оптическом волноводе с показателями преломления обкладок $n_{1}$ и $n_{2}$ и показателем преломления сердцевины $n_{0}$

Fundamental harmonic

Second

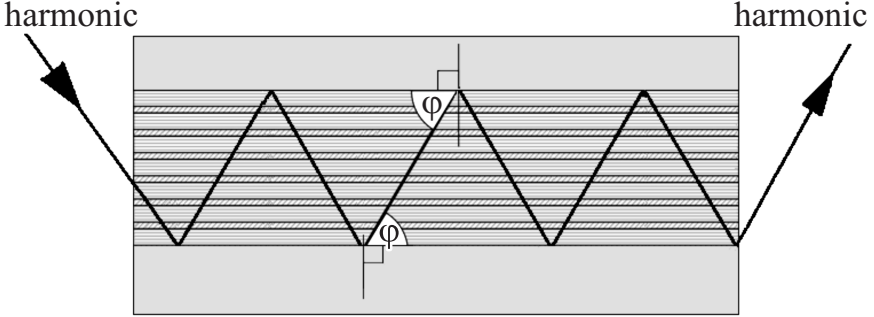

Рис. 1. Схематическое изображение структуры метаматериала с подавленной дисперсией показателя преломления. 
дисперсионное уравнение имеет вид

$$
V=\pi m+\arctan \left(\sqrt{n_{\mathrm{eff}}^{2}-n_{1}^{2}} / n^{\prime}\right)+\arctan \left(\sqrt{n_{\mathrm{eff}}^{2}-n_{2}^{2}} / n^{\prime}\right),
$$

где $V=k h n^{\prime}, n^{\prime}=\sqrt{n_{0}^{2}-n_{\text {eff }}^{2}}, n_{\text {eff }}$ - эффективный показатель преломления волновода, $h$ - толщина активной области, $m$ - целое число.

Таким образом, каждая длина волны имеет свой угол $\varphi$ распространения вдоль волновода. Если материал сердцевины волновода представляет собой рассмотренный выше ФК с анизотропным показателем преломления, имеет смысл найти самосогласованное решение уравнений (3) и (4), которое и будет описывать распространение света по такому волноводу. Связь между этими уравнениями задается углом распространения, который теперь фиксирован для каждой длины волны и определяется толщиной волновода, структурой ФК и свойствами материала обкладок. При решении уравнения (4) нужно считать, что $k=\sqrt{q^{2}+k_{z}^{2}}$. Кроме того, может быть формально учтена материальная дисперсия показателей преломления обкладок, т.е. $n_{1}=n_{1}(\omega)$, $n_{2}=n_{2}(\omega)$.

Нас будут интересовать решения, отвечающие $m=0$, что соответствует нулевым модам как для основной частоты, так и для второй гармоники. При этом в идеале волновод должен быть одномодовым как для основной, так и для преобразованной волны.

Нами было проведено решение уравнений (3), (4) для симметричного волновода с обкладками из твердого раствора $\mathrm{Al}_{x} \mathrm{Ga}_{1-x} \mathrm{~N}$ и сердцевиной в виде чередующихся слоев нитрида алюминия собственной проводимости и нитрида алюминия (толщиной $b=1 \mathrm{~nm}$ ), легированного до поверхностной концентрации $N_{s}=6 \cdot 10^{14} \mathrm{~cm}^{-2}$. При этом длина волны накачки принята равной $1100 \mathrm{~nm}$. Расчеты показывают, что длина когерентности может

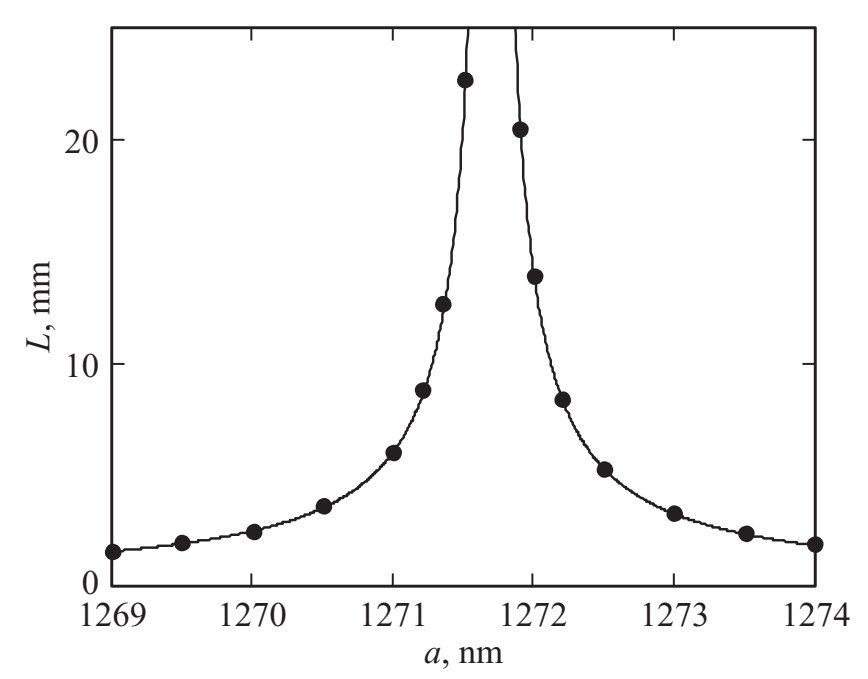

Рис. 2. Зависимость длины когерентности от толщины слоя собственной проводимости при базовой длине волны $1100 \mathrm{~nm}$ и общей толщине волновода $12.7 \mu \mathrm{m}$.

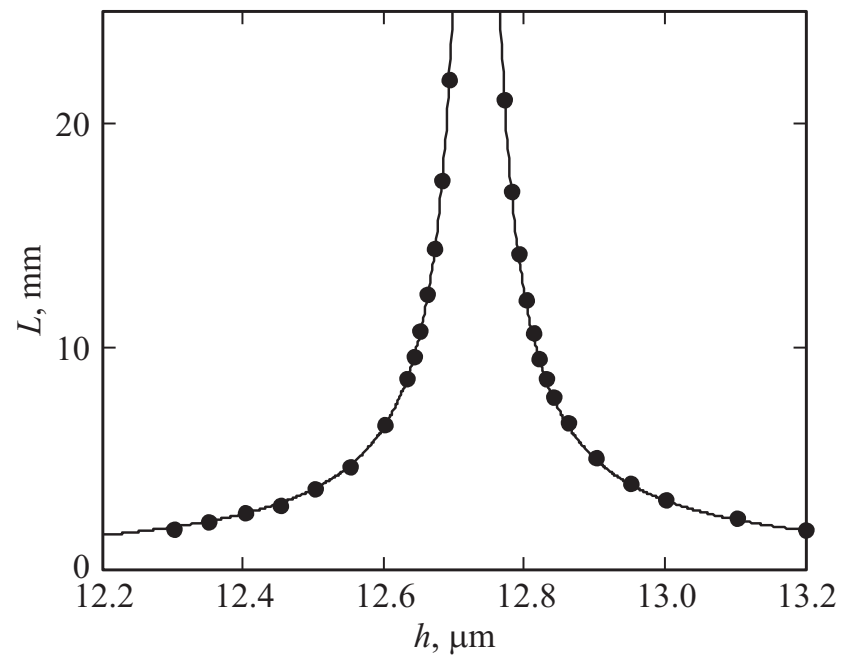

Рис. 3. Зависимость длины когерентности от толщины волновода при базовой длине волны $1100 \mathrm{~nm}$ и толщине слоя собственной проводимости $1272 \mathrm{~nm}$.

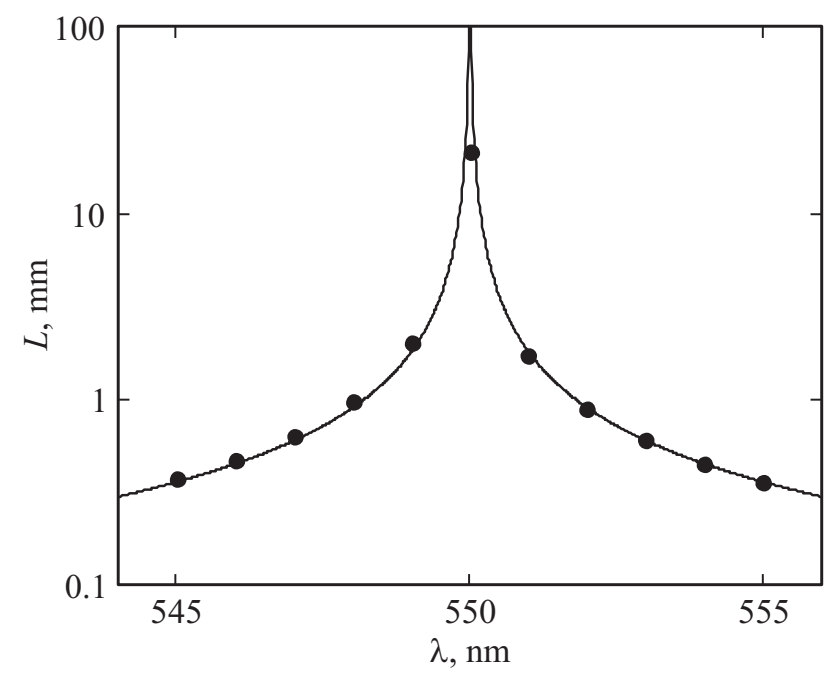

Рис. 4. Зависимость длины когерентности от длины волны второй гармоники для структуры из десяти пар слоев при толщине слоя собственной проводимости $1272 \mathrm{~nm}$.

достигать $25 \mathrm{~mm}$. При этом она зависит от толщины слоя собственной проводимости $a$, толщины волновода $h=j(a+b)$, где $j-$ число периодов ФК, показателей преломления обкладок $n_{1}=n_{2}$ (этот параметр определяется долей $x$ алюминия в твердом растворе $\mathrm{Al}_{x} \mathrm{Ga}_{1-x} \mathrm{~N}$ ).

На рис. 2-4 приведены результаты расчетов длины когерентности волновода, в сердцевине которого расположен ФК из десяти чередующихся слоев, мольная доля алюминия в материале обкладок $x=0.2$. Точками показаны результаты расчета, сплошные линии проведены для удобства.

На рис. 2 показана зависимость длины когерентности $L$ от толщины диэлектрического слоя метаматериала $a$ при фиксированной толщине волновода 
$h=12.7 \mu \mathrm{m}$. Видно, что изменение толщины приводит к падению длины когерентности, при этом ширина пика на высоте $L=1 \mathrm{~cm}$ составляет порядка $1.2 \mathrm{~nm}$, что значительно больше технологического предела точности толщины эпитаксиального слоя.

На рис. 3 показана зависимость длины когерентности от толщины $h$ волновода при $a=1272 \mathrm{~nm}$. Ширина пика на уровне $L=1 \mathrm{~cm}$ составляет около $250 \mathrm{~nm}$, что также укладывается в технологические ограничения.

На рис. 4 представлена зависимость длины когерентности от длины волны второй гармоники $\lambda$ при фиксированных $a=1272 \mathrm{~nm}, h=12.7 \mu \mathrm{m}$. Устройство демонстрирует высокую чувствительность к длине волны накачки: отклонение на $1 \mathrm{~nm}$ понижает длину когерентности с 25 до $1.5 \mathrm{~mm}$.

\section{4. Заключение}

Мы показали, что плоский трехслойный волновод с фотонно-кристаллической сердцевиной может обеспечивать истинный синхронизм фаз при генерации второй гармоники в оптическом диапазоне длин волн за счет подавления как материальной дисперсии в обкладках и в активной области, так и волноводной дисперсии. Это достигается использованием ФК с чередующимися слоями полупроводника собственной проводимости и сильнолегированного полупроводника с отрицательной диэлектрической проницаемостью. Подавление дисперсии происходит при этом за счет различия дисперсии показателей преломления собственного полупроводника и „металлического“ слоя. Длина когерентности волн с длинами 1100 и $550 \mathrm{~nm}$ превышает $2 \mathrm{~cm}$, что на несколько порядков выше длины когерентности в наиболее распространенных современных устройствах, осуществляющих генерацию второй гармоники в оптическом диапазоне $[2,3,10]$. Волновод представляет собой обкладки из твердого раствора $\mathrm{AlGaN}$ и сердцевину из чередующихся слоев $\mathrm{AlN}$ собственной проводимости и сильнолегированного AlN, обладающего металлической проводимостью. При этом волновод остается одномодовым для излучения накачки. Важные технологические параметры, такие как толщины слоев и толщина сердцевины волновода, влияют на длину когерентности сравнительно слабо (рис. 2,3). Основным недостатком предлагаемого способа преобразования излучения является высокая чувствительность к длине волны (рис. 4).

\section{Список литературы}

[1] A. Christ, T. Zentgraf, J. Kuhl, S.G. Tikhodeev, N.A. Gippius, H. Gissen. Phys. Rev. B 70, 125113 (2004).

[2] H. Liang, Y. He, R. Luo, Q. Lin. Opt. Express 24, 29444 (2016).

[3] N. Nouri, M. Zavvari. IEEE Photon. Technol. Lett. 28, 2199 (2016).

[4] S. Choudhary, K. Nouri, L. Elsaie. Lasers Med. Sci. 24, 971 (2009).
[5] A. Boutier, J.M. Most. In: Laser velocimetry in fluid mechanics / Ed. A. Boutier. John Wiley \& Sons, Inc., Hoboken, USA (2012). Ch. 3.

[6] E. Simbuerger, T. Pflanz, A. Masters. Confocal microscopy: new lasers enhance live cell imaging. Wiley-VCH Verlag, Weinheim (2008). P. 10-13.

[7] N. Mattiucci, G. D'Aguanno, M. Scalora, M.J. Bloemer. J. Opt. Soc. Am. B 24, 877 (2007).

[8] J. Pastrňák, L. Roskovcová. Phys. Status. Solidi B 14, K5 (1966).

[9] G.M. Savchenko, V.V. Dudelev, K.K. Soboleva, V.V. Lundin, A.V. Sakharov, E.A. Kognovitskaya, S.N. Losev, A.G. Deryagin, V.I. Kuchinskii, N.S. Averkiev, G.S. Sokolovskii, Tech. Phys. Lett. 42, (10) 1041 (2016).

[10] M.M. Fejer, G.A. Magel, D.H. Jundt, R.L. Byer. IEEE J. Quantum Electron. 28, 2631 (1992). 